\title{
Políticas sociais e as perspectivas de ampliação de direitos no Mercosul e em áreas fronteiriças - inovações e tendências
}

\author{
Vera Maria Ribeiro Nogueira \\ Helenara Silveira Fagundes \\ Carla Gabriela Cavini Bontempo
}

\section{SciELO Books / SciELO Livros / SciELO Libros}

NOGUEIRA, V. M. R., FAGUNDES, H. S., and BONTEMPO, C. G. C. Políticas sociais e as perspectivas de ampliação de direitos no Mercosul e em áreas fronteiriças - inovações e tendências. In: COSTA, L. C., NOGUEIRA, V. M. R., and SILVA, V. R., orgs. A política social na América do Sul: perspectivas e desafios no século XXI [online]. Ponta Grossa: Editora UEPG, 2013, pp. 99-112 ISBN 978-85-7798-231-8. Available from: doi: 10.7476/9788577982318.0005. Also available in ePUB from: http://books.scielo.org/id/rfv9p/epub/costa-9788577982318.epub.

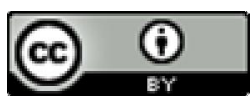

All the contents of this work, except where otherwise noted, is licensed under a Creative Commons Attribution 4.0 International license.

Todo o conteúdo deste trabalho, exceto quando houver ressalva, é publicado sob a licença Creative Commons Atribição 4.0.

Todo el contenido de esta obra, excepto donde se indique lo contrario, está bajo licencia de la licencia Creative Commons Reconocimento 4.0. 


\section{Políticas sociais e as perspectivas de ampliação de direitos no Mercosul e em áreas fronteiriças - inovações e tendências \\ Vera Maria Ribeiro Nogueira; Helenara Silveira Fagundes; Carla Gabriela Cavini Bontempo}

\section{Introdução}

A comemoração dos vinte anos do Mercosul enseja/convida a uma reflexão acerca das consequências sociopolíticas e jurídicas decorrentes de sua implementação no sul da América Latina. A sua constituição, obedecendo a ordenamentos econômicos, ocasionou, ainda que em escala reduzida, impactos na área social, favorecendo a emergência de atores políticos e instituindo inovações no plano jurídico-administrativo. A preocupação com os aspectos sociais, a partir de 2002, segundo Draibe (2006) e Di Pietro (2003), deve-se à configuração do poder na América Latina, desde os anos 2000, com governantes políticos de centro-esquerda assumindo a liderança dos países do bloco, apontando, inclusive, para uma incipiente solidariedade entre eles.

Uma das consequências indiretas da constituição do Mercosul foi a metamorfose ocorrida em relação às fronteiras, as quais passam a ser objeto de preocupação governamental dos países, não mais por serem áreas de segurança nacional, mas especialmente por serem corredores econômicos de trânsito de bens, serviços e mercadorias. Além destes dois aspectos, a faixa fronteiriça é reconhecida pela perversa desigualdade territorial, onde a violência e a negação de direitos são uma constante. A metamorfose indicada se expressa em aportes teóricos derivados da geografia política, sobretudo a noção de territorialidade (SANTOS, 2000), adensando-se o conceito de fronteira como área de transição e não unicamente de limite político, e no campo das políticas públicas, há a implementação de programas nacionais visando ao desenvolvimento das áreas de fronteira (BRASIL, 2004, 2005).

Um aspecto significativo relacionado à ampliação dos direitos é que os interesses econômicos de expansão dos mercados nacionais, aliados aos novos aportes sobre fronteira e ao reconhecimento da debilidade social e econômica da linha de fronteira, com a ampliação e maior visibilidade de graves aspectos da questão social, ocasionaram medidas sócio-jurídicas sinalizadoras de uma tendência de cidadania para além dos Estados nacionais. Não se pode deixar de reconhecer que, se no plano formal os novos acordos e pactos bilaterais apontam para uma área de cidadania transnacional, na realidade tais medidas são ainda pouco conhecidas e aplicadas nos espaços fronteiriços (NOGUEIRA, SILVEIRA, BONTEMPO, 2011; PREUSS, 2011). 
Justifica-se também a preocupação com as áreas ${ }^{1}$ fronteiriças devido ao extenso limite territorial brasileiro, pois a linha de fronteira é de $16.886 \mathrm{~km}$, ocupando $27 \%$ do território nacional e onde vivem 11 milhões de pessoas. Existem 588 municípios na zona de fronteira e 122 municípios na linha da fronteira, sendo que 10 estados brasileiros limitam-se com dez países vizinhos. Esta magnitude dá a dimensão da importância da questão fronteiriça.

Alerta-se para a situação estratégica das fronteiras e os riscos a ela associados, com represálias aos indivíduos não nacionais dos países limítrofes, sempre levando a sérios conflitos que não contribuem para a integração regional. Tal questão, se não for adequadamente administrada, poderá ocasionar um refluxo na concepção mais aberta de fronteira, voltando a ser unicamente objeto de práticas policiais e não ampliando os processos de integração iniciados a partir de $2002^{2}$ e, consequentemente, o desenvolvimento destas áreas.

Tendo em vista os aspectos mencionados, o objetivo deste texto é sintetizar algumas inovações e tendências nos campos sociopolítico e jurídico observados na institucionalidade do Mercosul e as consequências na faixa de fronteira. Observa-se que as ideias e os elementos trazidos para o debate são frutos das análises e reflexões decorrentes dos estudos realizados junto ao Núcleo de Estudos Estado, Sociedade Civil, Políticas Públicas e Serviço Social - da Universidade Federal de Santa Catarina - NESPP/UFSC, linha de pesquisa Estado, Sociedade Civil, Políticas Públicas e Serviço Social e Grupo de Estudo Políticas Sociais, Cidadania e Serviço Social na linha de pesquisa Fronteira, direitos sociais, políticas de proteção à saúde e política de assistência social, do Programa de Pós-Graduação da Universidade Católica de Pelotas, com a cooperação do Conselho Nacional de Desenvolvimento Científico e Tecnológico - CNPq, desde 2002.

\section{Políticas Públicas}

Inicialmente, destacam-se três aspectos de ordem teórica que sustentam a argumentação deste texto.

\footnotetext{
1 A Legislação Brasileira - Lei n 6.634, de 2 de maio de 1979, regulamentada pelo Decreto $\mathrm{n}^{\circ}$ 85.064, de 26 de agosto de 1980, ratificada pela Constituição Federal de 1988, define como faixa de fronteira a área compreendida dentro de cento e cinquenta quilômetros perpendiculares à linha do limite do território brasileiro. Atualmente se estabeleceu o uso do termo linha de fronteira, que seria o território municipal que compõe a divisa nacional. Cidades-gêmeas são as que confrontam com outras de outro país, sem limites físicos marcantes (BRASIL, 2002).

O Decreto 7.496 institui o Plano Estratégico de Fronteiras para fortalecer a prevenção, controle, fiscalização e repressão dos delitos transfronteiriços e dos delitos praticados na faixa de fronteira brasileira (BRASIL, 2011).
} 
Primeiro: parte-se do suposto que, ao tratar de proteção social e garantia de direitos, está se tratando de uma política pública para a garantia de direitos, seja a dos direitos fundamentais clássicos, como o direito civil ou político e, em tempos mais recentes, o direito social, que somente é possível a partir do Estado democrático de Direito e não de qualquer outro tipo de regime político. Nesta linha de raciocínio, política pública é mais do que simplesmente uma intervenção do Estado na proteção social, sendo a forma contemporânea de exercício de poder nas sociedades democráticas e fruto da complexa interação do Estado e da sociedade (DI GIOVANNI, 2009).

É nesta interação Estado e sociedade que se definem as situações consideradas problemáticas, bem como as formas, os conteúdos, os meios, o sentido e as modalidades de intervenção sobre o social. A transposição da proteção social para blocos regionais exige pactos e interações dos vários Estados nacionais que, a médio e a longo prazo, sinalizam para uma perspectiva de cidadania ampliada e uma nova ordem jurídico-administrativa em termos de garantia dos direitos.

Segundo: as formas, os conteúdos, os meios, o sentido e as modalidades de proteção social são distintos em cada um dos países, pois decorrem de processos históricos, econômicos e culturais de longa data. São construções que se fizeram nos marcos dos Estados-nação que mantêm, até hoje, assimetrias entre si. Se no passado recente estas assimetrias eram menos visíveis e as informações eram lentas e demoradas, atualmente a ampliação dos meios de comunicação, tanto físicos como midiáticos, em termos de qualidade e quantidade, tornam mais evidentes as diferenças, contribuindo para favorecer as lutas políticas em torno da igualdade. Isso explica por que, em países com processos históricos similares, as formas de posicionamento das elites políticas e as exigências estruturais encaminham posições distintas em relação aos ordenamentos e regulações sociais.

Esse aspecto é fundamental para pensar a proteção social e os direitos sociais no Mercosul. As dinâmicas dos movimentos de regionalização e as formações globais, por sua vez, exigem um novo reordenamento aos Estados nacionais, impondo desafios jurídicos, administrativos e institucionais à compatibilização de demandas nacionais com as globais, em termos de direitos sociais e responsabilidades em sua garantia.

Terceiro: as políticas públicas não são construções independentes, pois somente ocorrem onde exista uma democracia no sentido moderno e pressupõem:

1. uma capacidade de planejamento, consolidada nas instituições estatais, do ponto de vista técnico, de gestão e do ponto de vista político; 
2. a coexistência e a independência de poderes e vigência de direitos de cidadania; e

3. a capacidade coletiva de formulação de agendas públicas, do exercício da cidadania e de uma cultura política capaz de sustentar esse cenário.

Tendo como referência tais pressupostos, é possível apontar aspectos visíveis das políticas públicas, e em constante interação, interdependência e organicidade, que seriam o que Di Giovanni (2009) denomina de estruturas elementares das políticas públicas

1. estrutura formal, composta pelos elementos: "teoria", práticas e objetivos/resultados;

2. estrutura substantiva, composta pelos elementos: atores, interesses e regras;

3. estrutura material, composta pelos elementos: financiamento, suportes, custos;

4. estrutura simbólica, composta pelos elementos: valores, saberes e linguagens.

A partir deste enquadramento teórico, podem ser destacadas algumas tendências relacionadas à proteção social e aos direitos no Mercosul.

No plano da estrutura formal: "teoria", práticas e objetivos/resultados - não se pode negar que as políticas sociais sofreram e vêm sofrendo uma alteração na teoria e nas práticas, condicionando resultados, em função do ideário neoliberal. O empobrecimento violento da população na "década perdida", vis a vis com a imposição da redução dos gastos sociais, obrigou os países a implementarem políticas de combate à pobreza, alterando o conteúdo das políticas com a prática da focalização, reduzindo as garantias previdenciárias e impondo reformas incrementais nos sistemas nacionais de proteção social, em nome da redução da pobreza extrema. As teorias que se assentavam no ideal de igualdade deixam de ser o "norte" das políticas sociais. Embora no campo econômico a orientação das agências multilaterais fosse a integração dos países em blocos regionais, a proteção social mantém-se como responsabilidade de cada Estado-parte e não se ampliaram as garantias sociais para o bloco com um todo. A única situação em que se apontou uma tendência para a expansão da cidadania para além dos espaços nacionais foram as iniciativas governamentais de programas na área de fronteiras, como se verá posteriormente.

Com a crise econômica do final dos anos 2000, altera-se novamente o cenário internacional, sendo que na América Latina o impacto negativo foi sentido, mas não tanto quanto nos países mais desenvolvidos, pelo menos por enquanto. Segundo Mirza (2011), os efeitos da crise não tiveram a gravidade 
das crises anteriores, o que se deve a um melhor manejo da política macroeconômica, à redução do endividamento e ao aumento das reservas internacionais. Houve um pequeno crescimento econômico entre 2000 e 2008, com o controle da inflação e a acumulação de reservas.

Mesmo assim, no plano da política social, a professora Potyara Pereira (2011) assinala que há um tensionamento no sentido da: 1. Direitização e deslegitimação do sistema de proteção construído sob a égide da igualdade. $\mathrm{Na}$ atualidade, a política social responde de forma muito conveniente ao mercado com reformas para excluir o número de protegidos pelo Estado; 2. Laborização da política social - a proteção assistencial é condicionada à busca e fomento à empregabilidade. Ou seja, a assistência é apenas um trampolim para o trabalho; 3. Descidadanização - o trabalho vem sendo cada vez mais dissociado da cidadania. Amplia-se o trabalho precário, sem garantias de direito. O crescimento da economia informal amplia o trabalho infantil e a exploração do trabalho de migrantes sem documentos.

Contrariando essa opinião, outros autores sinalizam para uma alteração positiva na área das políticas sociais, ainda que no plano discursivo. A CEPAL, no documento $A$ bora da Igualdade - brechas para fechar e caminhos para abrir, de 2010, menciona taxativamente que os princípios mais estruturantes que caracterizaram os estados de bem-estar da era pós-guerra estão ganhando espaço em relação a abordagens mais individualistas, centradas no mercado. Anuncia também o declínio da focalização como princípio balizador privilegiado da assistência social. Demonstra renovada preocupação acerca da desigualdade e reconhece a limitação das lógicas familiares e de mercado para o enfrentamento da desigualdade e dos riscos. Deste modo, o Estado adquire maior peso estratégico na busca de soluções para problemas de desigualdade e bem-estar.

No plano da estrutura substantiva: composta pelos elementos - atores, interesses e regras -, ocorre um fenômeno peculiar. Há uma transformação nas formas de mobilização e participação sindicais tradicionais e dos movimentos sociais clássicos e a emergência de atores políticos de dois espectros - um voltado para fortalecer a institucionalidade do Mercosul e outro vinculado às demandas particulares e à dimensão social do bloco.

No primeiro caso, encontram-se os mecanismos que conformariam a institucionalidade política forte, o núcleo duro do bloco, como o Parlamento do Mercosul. Se até 2010, os parlamentares eram indicados pelos governos dos países do bloco, a partir de 2012, há a indicação de eleições diretas, sendo que o Brasil deverá ampliar a sua representação de 18 para 37 parlamentares (MERCOSUR, 2011). Além do Parlamento, vão se constituindo novos atores no campo técnico-administrativo, como é o caso do Instituto Social do Mercosul - ISM, criado em 2005, com sede em Assunção. Entre os objetivos do ISM, estão: contribuir para a consolidação da dimensão social como um eixo fundamental 
no desenvolvimento do Mercosul, contribuir para a superação das assimetrias, colaborar tecnicamente com o desenho das políticas sociais regionais, sistematizar e atualizar indicadores sociais regionais, identificar e divulgar boas práticas em matéria social, promover mecanismos de cooperação horizontal e identificar fontes de financiamento (Instituto Social do Mercosur, 2011).

Outra iniciativa importante para o campo da proteção social foi a criação do Instituto de Políticas Públicas de Direitos Humanos - IPPDH, em 2009, com sede em Buenos Aires. Tem como objetivo contribuir para o fortalecimento do Estado de Direito dos Estados-partes, mediante o desenho e o seguimento de políticas públicas de direitos humanos, para aconsolidação dos direitos humanos como um eixo fundamental da identidade e do desenvolvimento do Mercosul.

Estas iniciativas vão sedimentar um desenho político-institucional que não pode ser desconsiderado na construção das agendas econômicas e sociais do bloco.

No segundo caso, relativo à dimensão social do bloco, duas iniciativas são emblemáticas: o Programa Mercosul Social e Solidário (PMSS), criado em 2003, e o Programa Somos Mercosul, inaugurado em 2005. Ambos reúnem uma diversidade de movimentos e organizações sociais do campo democrático-popular, como movimentos de base, ONGs, cooperativas, sindicatos, organizações de gênero, juventude, meio ambiente, direitos humanos, entre outros.

O Programa "Somos Mercosul" situa-se como um programa de ações sociais, políticas e culturais, constituído por meio da iniciativa entre os governos e a sociedade civil organizada dos países-membro do Mercosul. Surgiu como resposta à demanda de maior participação social no processo de integração regional e, por este motivo, expressa, como objetivo central, a "promoção da cidadania no processo de integração regional, criando novos espaços para que a sociedade civil e os governos locais possam debater, formular demandas e participar dos processos decisórios" (Programa "Somos Mercosul", 2008). O programa busca desencadear ações na direção de tornar os benefícios do processo de integração acessíveis ao conjunto da população dos países-membros, fomentando a criação de uma cidadania regional como ferramenta para a integração e a transformação social.

O programa "Mercosul Social e Solidário" - PMSS - consiste em uma plataforma de ação, integrada por dezoito organizações não governamentais de âmbito nacional (Argentina, Brasil, Chile, Paraguai e Uruguai), e aproximadamente trezentas organizações sociais de base representantes de camponeses, mulheres, jovens, povos originários, entre outros. Trabalha a dimensão social da integração regional Mercosul mediante dupla estratégia: favorecer e promover a articulação social desde as organizações de base e realizar um 
trabalho conjunto com outras iniciativas que estejam voltadas a implantar e dar visibilidade aos temas sociais no Mercosul. Contudo, mesmo diante de objetivos comuns, as organizações sociais do PMSS possuem diferentes visões a respeito das políticas públicas: a primeira é marcada pela autonomia frente ao Estado e autodeterminação relacionada à prática política; - a segunda visão está vinculada à ideia de "controle social" e na formulação das agendas políticas do bloco; a terceira e última visão propõe a transformação da realidade e a construção do poder e de um novo Estado.

No plano da estrutura material: composta pelos elementos: financiamento, suportes, custos -, alguns elementos podem contribuir para pensar as tendências das políticas sociais no Mercosul.

Um aspecto importante a ressaltar é a criação do Fundo de Convergência Estrutural e Fortalecimento Institucional do Mercosul (FOCEM). É um mecanismo que tem por finalidade aprofundar o processo de integração regional no Cone Sul, por meio da redução das assimetrias, do incentivo à competitividade e do estímulo à coesão social entre os países-membros do bloco.

Criado em dezembro de 2004, e estabelecido em junho de 2005, o fundo se destina a financiar projetos para melhorar a infraestrutura das economias menores e regiões menos desenvolvidas do Mercosul, impulsionar a produtividade econômica dos 'Estados-partes', promover o desenvolvimento social, especialmente nas zonas de fronteira, e apoiar o funcionamento da estrutura institucional do bloco.

O FOCEM é composto por contribuições não reembolsáveis que totalizam US $\$ 100$ milhões (cem milhões de dólares) por ano. Os aportes são feitos em quotas semestrais pelos Estados-partes do Mercosul, na proporção histórica do PIB de cada um deles. Desse modo, a Argentina é responsável por $27 \%$ (vinte e sete por cento) dos recursos; o Brasil, por 70\% (setenta por cento); o Paraguai, por 1\% (um por cento); e o Uruguai, por $2 \%$ (dois por cento).

Atualmente, o FOCEM financia quatro programas vinculados aos seus objetivos. O primeiro programa refere-se ao desenvolvimento e ao ajuste estrutural das economias menores e menos desenvolvidas, incluindo a melhoria dos sistemas de integração de fronteiras; o segundo programa destina-se à promoção da competitividade produtiva do Mercosul, inclusive ao incentivo de processos de reconversão produtiva e laboral que favoreçam o comércio interno do bloco; o terceiro programa serve ao desenvolvimento social, especialmente nas regiões fronteiriças; e o quarto programa busca o aperfeiçoamento da estrutura institucional do Mercosul.

Entre os projetos financiados pelo FOCEM, na área da proteção social, destacam-se a construção e a recuperação de edifícios escolares na fronteira da província de Santa Fé, Argentina; Implantação da biblioteca e do Instituto 
Mercosul de Estudos Avançados da UNILA, Obras de Engenharia do Sistema de Esgotamento Sanitário de Ponta Porã e São Borja, no Brasil; Mercosul Habitat de Promoção Social, Fortalecimento de Capital Humano e Social em assentamentos em condições de Pobreza em San Lorenzo, Ciudad del Este e Coronel Oviedo, Mercosur ROGA - programa de combate à pobreza e acesso à saúde, alimentação e educação de regiões empobrecidas e de fronteiras, Programa de Apoio Integral a Microempresas, Laboratório para controle de alimentos (prevenção do patrimônio pecuário do Paraguai e proteção da saúde pública, animal e ambiental), promoção de acesso à água potável e saneamento básico em comunidades em situação de pobreza e extrema pobreza em Yporã, construção e melhoramento de sistema de esgoto e água potável em comunidades indígenas e rurais no Paraguai; fortalecimento de comunidades locais com projetos de economia social de fronteiras, intervenções múltiplas em assentamentos colocados em territórios de fronteira com situação de extrema pobreza e emergência sanitária, ambiental e habitacional nas cidades de Paysandu, Artigas, Colónia e Rocha, no Uruguai (MERCOSUL, 2011).

No plano da estrutura simbólica: composta pelos elementos: valores, saberes e linguagens - as intervenções públicas no campo social, nos Estados-parte, mantêm comportamentos corporativos, sendo também que as práticas do clientelismo e do patrimonialismo são comuns, conforme se identificou em regiões de fronteiras (AGUSTINI, 2009; NOGUEIRA, AGUSTINI, 2010).

Outro aspecto que impacta negativamente nos programas nacionais desenvolvidos nas áreas de fronteiras é o tipo de institucionalidade da área social, com um delineamento pró-mercado ou então com pouca solidez institucional, permeada pelos particularismos de interesses e ausência de quadros técnicos competentes e necessários para implementar políticas públicas. Devido a esse fato, há, conforme estudos recentes, um hiato entre as determinações legais e programáticas e o que é realmente implementado (PREUSS, 2011; NOGUEIRA, 2010; AGUSTINI, 2009). Ou seja, não se encontra uma política social caracterizada pela existência de uma estratégia de longo prazo, da continuidade dos atores, da existência de espaços de coordenação, do desenvolvimento da capacidade técnica, de mecanismos de coleta e análise de informações e participação dos atores sociais.

Fenômenos e processos sinalizadores da desnacionalização e uma nova perspectiva de cidadania na esfera de proteção e garantia de direitos

No espaço geopolítico das fronteiras internacionais, seja linha, área ou faixa de fronteira, e sobretudo nas denominadas cidades-gêmeas, o questionamento sobre cidadania e direitos sociais é ampliado por duas razões - são regiões usualmente distantes dos circuitos nacionais e espelham as similitudes, 
as simetrias/assimetrias e as contradições entre os países. Simultaneamente a este fenômeno, e talvez provocado por ele, além de intensificado devido às pretensas abolições fronteiriças e aos processos migratórios, o debate sobre os direitos volta à cena, envolvendo tradicionais e novos atores políticos que se localizam tanto em espaços nacionalizados como globalizados.

As fronteiras se desenham como espaços territoriais onde se aguçam as distinções quanto ao atendimento às demandas derivadas das condições existenciais básicas e exacerbam a evidência dos limites dos direitos pensados na ordem jurídico-administrativa dos Estados nacionais. Por esta razão, as demandas socioassistenciais e a impossibilidade de resolução nos espaços nacionais, e face à possibilidade de resolução do outro lado da fronteira, tensionam os limites nacionais e fortalecem as lutas políticas para a ampliação da cidadania social para além do limite legal.

Os direitos sociais, ao longo da linha da fronteira, embora sob a ordem jurídica do mesmo Estado, apresentam patamares distintos de garantia e abrangência, revelando a natureza, o papel e a função estatal em cada espaço peculiar, levando a distintos padrões de cidadania quando se refere à igualdade de direitos, especialmente os sociopolíticos. Os fatores que levam a esta distinção são relacionados às formas históricas de ocupação territorial e questões geopolíticas vinculadas a alianças entre os países e políticas nacionais implementadas em épocas anteriores.

\section{No plano jurídico-administrativo}

Neste plano, considera-se o Decreto n ${ }^{\circ} 5.105$, de 14 de junho de 2004, no qual os governos brasileiro e uruguaio formalizam o Acordo para a Permissão de Residência, Estudo e Trabalho, Previdência Social e concessão de documento especial a nacionais fronteiriços brasileiros e uruguaios, residentes em dezoito localidades fronteiriças. Posteriormente, foi ampliado através de um ajuste complementar ao acordo para a prestação de serviços de saúde, firmado no Rio de Janeiro, em 28 de novembro de 2008, aprovado pelo Decreto Legislativo $n^{\circ} 933 / 2009$ e promulgado pelo Decreto $n^{\circ} 7239 / 2010$. Tal acordo torna a sua região de abrangência uma faixa onde não existe a cidadania brasileira ou uruguaia, mas uma cidadania regionalizada em termos de garantia de direitos sociais (2004).

O acordo entre a República Federativa do Brasil e a República Argentina sobre Localidades Fronteiriças Vinculadas, celebrado em Puerto Iguazú, em 30 de novembro de 2005, estabelece o direito dos residentes em cidades localizadas na fronteira a uma carteira de trânsito vicinal fronteiriço, com a qual poderão trabalhar no país vizinho, com direitos trabalhistas e previdenciários. 
Terão ainda direito ao ensino público e aos serviços públicos de saúde "em condições de gratuidade e reciprocidade" (2005).

O Pacto pela Saúde, formalizado através da Portaria no 2.607, de 10 de dezembro de 2004, é um conjunto de reformas institucionais pactuado entre as três esferas de gestão (União, estados e municípios) do Sistema Único de Saúde, com o objetivo de promover inovações nos processos e instrumentos de gestão. Define regiões de saúde, as quais podem ser constituídas por municípios de mais de um país, desde que situados em regiões de fronteiras. Essa é a primeira indicação que considera a fronteira como uma continuidade territorial nas fronteiras para além do limite nacional.

O Programa Sistema Integrado de Saúde - SIS Fronteiras, Instituído pela Portaria GM 1.120/05, é um projeto do Ministério da Saúde do Brasil, concebido para promover a integração de ações e serviços de saúde na região de fronteira e contribuir para a organização e o fortalecimento dos sistemas locais de saúde nos municípios fronteiriços. O Projeto pretende estimular o planejamento e a implantação de ações e acordos bilaterais ou multilaterais entre os países que compartilham fronteiras entre si, por intermédio de um diagnóstico homogêneo da situação de saúde para além dos limites da fronteira geopolítica brasileira.

\section{No plano dos atores políticos}

Destacam-se os gestores locais de saúde - o papel desempenhado por alguns gestores locais de saúde vem favorecendo a expansão da cidadania, processo este que pode ser analisado a partir de dois ângulos. O primeiro, quando pressionado pela exigência de resolução de problemas fitossanitários, impulsiona ações à revelia dos ordenamentos jurídicos nacionais, como, por exemplo, o trânsito de ambulâncias entre os países, as campanhas de vacinação realizadas coletivamente entre os países, os acordos informais entre gestores para suprir o atendimento, como ocorreu e ocorre em Santana do Livramento-BR/Rivera-UY. Nestes casos, são estabelecidos acordos formais entre gestores, mesmo sem respaldo legal para atendimento de alta e média complexidade. O mesmo se verificou em Santa Vitória do Palmar-BR, com a contratação de médicos uruguaios (proibido por lei no Brasil sem o devido reconhecimento e validação do diploma e da matrícula nos órgãos de fiscalização profissional) para suprir a ausência destes profissionais devido às greves ou inexistência. Tal situação foi a cunha para a regulação do trânsito de profissionais interfronteiras no Uruguai, através do Ajuste Complementar ao acordo anteriormente mencionado. O segundo ângulo é uma perspectiva ampliada de cidadania, reconhecendo aos não nacionais os mesmos direitos dos brasileiros aos bens e serviços de saúde, derivado do reconhecimento 
do direito universal à saúde e de uma igualdade intrínseca entre os homens. Essa posição foi encontrada de forma preponderante entre os gestores da fronteira uruguaia.

Outros atores políticos têm sido os profissionais da área da saúde especialmente enfermeiros e assistentes sociais - com uma visão de cidadania ampliada e que, frente à reticência dos gestores em atender aos não nacionais, ou atender unicamente os casos de urgência e emergência, enviam os casos para o Ministério Público que, usualmente, os obriga ao atendimento integral com base nos princípios constitucionais da universalidade e integralidade do sistema de saúde brasileiro.

\section{Conclusão}

A constituição do Mercosul trouxe consequências sociopolíticas e jurídicas significativas, pois embora tenha sido originariamente decorrente de ordenamentos econômicos, viabilizou impactos relevantes na área social. Vem sedimentando um desenho político institucional possibilitando novas agendas que buscam reduzir as assimetrias entre os países, incrementando a participação de novos atores políticos e promovendo mecanismos de cooperação horizontal. Reconhece-se que a frágil institucionalidade das políticas de proteção social, decorrentes das formas de ocupação territorial e acordos entre elites e frações de elites, é ainda um obstáculo à igualdade social efetiva entre a população dos países integrantes do bloco.

Destaca-se ainda que, em decorrência destes fenômenos, a interação habitual, nos diversos planos da vida cotidiana, altera a percepção dos residentes em duas dimensões relacionadas à categorização da cidadania. Enquanto na fronteira com o Uruguai se diluem os limites entre os países, instituindo-se, no plano simbólico, um espaço comum que é designado simplesmente como fronteira, onde todos são cidadãos da fronteira, em contrapartida, no limite com o Paraguai, a percepção é frontalmente diversa, com a marca da igualdade/diferença, principalmente devido às assimetrias econômicas e sociais severas, gerando uma posição de confronto. No caso da fronteira Argentina-Brasil, mantém-se a marca da igualdade/diferença, embora se identifique maior simetria socioeconômica. Nestes casos, a linha de fronteira volta a ser demarcatória dos limites territoriais e, consequentemente, da marca de cidadania nacional.

Pode-se afirmar que, ao serem espaços territoriais onde coexistem a confluência das distinções quanto ao atendimento às condições existenciais básicas e à evidência dos limites dos direitos pensados em relação aos Estados nacionais, as fronteiras estudadas têm se constituído em focos de lutas políticas para a ampliação da cidadania. As experiências de integração a partir das 
iniciativas dos atores políticos, ainda que incipientes, têm servido como estímulo para que outros municípios fronteiriços desenvolvam ações semelhantes.

A proteção social e a garantia dos direitos sociais, em que pesem as conquistas até hoje, são as únicas garantias na direção de uma sociedade mais justa e igualitária, nos âmbitos local, regional, nacional e internacional.

\section{Referências}

AGUSTINI. J. A descentralização da política nacional de saúde e sua institucionalidade nos sistemas municipais na linha da fronteira Mercosul. Dissertação (Mestrado em Serviço Social). Universidade Federal de Santa Catarina. Florianópolis, 2009.

BRASIL. Presidência da República. Lei n. 6.634, de 2 de maio de 1979. Dispõe sobre a Faixa de Fronteira, altera o Decreto-lei n ${ }^{\circ} 1.135$, de 3 de dezembro de 1970, e dá outras providências. Disponível em: < http://www.planalto.gov.br/ccivil_03/leis/ L6634.htm>. Acesso em: 20 setembro 2011.

Lei 907, de 21 de novembro de 2003. Prevê a igualdade de direitos entre brasileiros e uruguaios. Disponível em $<$ http://www.presidencia.gov. br/casacivil/>. Acesso em: 27 junho 2005.

. Decreto n. 5.105, de 14 de junho de 2004. Promulga o Acordo entre o Governo da República Federativa do Brasil e o Governo da República Oriental do Uruguai para Permissão de Residência, Estudo e Trabalho a Nacionais Fronteiriços Brasileiros e Uruguaios, de 21 de agosto de 2002. Acordo sobre localidades fronteiriças vinculadas. Disponível em: <http://www2.mre.gov.br/dai/b_argt_402_5639.htm> . Acesso em: julho 2006.

Ministério da Integração Nacional. Proposta de reestruturação do programa de desenvolvimento da faixa de fronteira. Brasília: MI/IICA, 2005. Disponível em < http://www.igeo.ufrj.br>. Acesso em: 09 maio 2006.

Programa de desenvolvimento de faixa de fronteira. 2005.

. Ministério da Saúde. Programa Sis Fronteiras. Disponível em: <http:// portal.saude.gov.br/portal/saude/profissional/area.cfm?id_area=1228>. Acesso em: 13 de março de 2006.

Pacto pela saúde. Disponível em: $<$ http://portal.saude.gov.br/ portal/saude/profissional/area.cfm?id_area=1021>. Acesso em: 22 maio 2008.

. Câmara dos Deputados. Decreto n.7.239, de 26 de Julho de 2010. Promulga o Ajuste Complementar ao Acordo para Permissão de Residência, Estudo e Trabalho a Nacionais Fronteiriços Brasileiros e Uruguaios, para Prestação de Serviços de Saú-de, firmado no Rio de Janeiro, em 28 de novembro de 2008. Disponível em: 
Políticas sociais e as perspectivas de ampliação de direitos no Mercosul e em ...

<http:/ /www2.camara.gov.br/legin/fed/decret/2010/decreto-7239-26-julho-2010607424-publicacaooriginal-128371-pe.html>. Acesso em: jul. de 2012.

Câmara dos Deputados. Decreto $\mathbf{n}^{\mathbf{0}} \mathbf{7 . 4 9 6}$, de 8 de Junho de 2011. Plano

Estratégico de Fronteiras. Disponível em: <http://www2.camara.gov.br/legin/fed/ decret/2011/decreto-7496-8-junho-2011-610751-publicacaooriginal-132772-pe. html>. Acesso em: 19 setembro 2011.

CEPAL. A hora da igualdade: brechas por fechar e caminhos para abrir. CEPAL. Brasília, 2010.

DI GIOVANNI, Geraldo. As estruturas elementares das políticas públicas. Campinas: NEPP/UNICAMP, 2009.

DI PIETRO, PAOLO, Luis José. La dimension social del Mercosur: recorrido institucional y perspectivas. Disponível em: < http://www.opalc.org/images/INRE/ mercosur\%20social.pdf>. Acesso em: 26 julho 2007.

DRAIBE, Sonia. Coesão social e integração regional: a agenda social do MERCOSUL e os grandes desafios das políticas sociais integradas. Rio de Janeiro. 2006. Cad. Saúde Pública, Rio de Janeiro, v.23, Sup. 2, p.174-183, 2007.

MERCOSUL. Fundo para convergência estrutural do Mercosul. Disponível em: $<$ http//mercosur.int/focem/>. Acesso em: 20 de setembro de 2011.

MERCOSUR Social e solidário. Disponível em:

$<$ http:/ / mercosursocialsolidaricessoo.org/index.php?option $=$ com_content\&task $=\mathrm{v}$ iew\&id=122\&Itemid=98> . Acesso em: 10 de agosto 2011 .

MERCOSUR. Parlamento del Mercosur. Disponível em: <htttp//www. parlamentodelmercosur.org >. Acesso em: 10 setembro 2011.

MERCOSUR. Somos Mercosur. Disponível em: <http://www.somosmercosur. org/>. Acesso em: 20 setembro 2011.

MIRZA, Christian A. O trabalho no século XXI e as particularidades no Mercosul. In: SIMPÓSIO: SAÚDE DO TRABALHADOR E PROTEÇÃO SOCIAL NO MERCOSUL, 2. Porto Alegre, 20 e 21 de junho de 2011.

NOGUEIRA, Vera M. Ribeiro; AGUSTINI, Josiane. A descentralização da política nacional de saúde nos sistemas municipais na linha da fronteira MERCOSUL. Serviço Social e Sociedade, 102. São Paulo, abril/junho, 2010.

.; DAL PRÁ, Keli R.. MERCOSUL: expressões das desigualdades em saúde na linha da fronteira. Ser Social (UnB), v. 1, 2006.

PEREIRA, P. A. P.; Política social contemporânea: concepções e configurações no contexto da crise capitalista. In: Seminário de Política Social do MERCOSUL, 3, Pelotas 2011. Anais... Pelotas: EDUCAT, 2011. 
PREUSS. Lislei T. O pacto pela saúde nas cidades gêmeas da fronteira do Rio Grande do Sul com a Argentina e o Uruguai. Tese (Doutorado em Serviço Social). Pontifícia Universidade Católica do Rio Grande do Sul. Porto Alegre. 2011.

SANTOS, Milton. O espaço do cidadão. 5.ed. São Paulo: Studio Nobel, 2000.

SILVA, Maria Geusina da. O local e o global na atenção às necessidades de saúde dos brasiguaios: análise da intervenção profissional do assistente social em Foz do Iguaçu. Dissertação (Mestrado em Serviço Social) Universidade Federal de Santa Catarina, Florianópolis, 2006. 